\title{
Tempos de Império: a trajetória da geometria como um saber escolar para o curso primário
}

\section{Wagner Rodrigues Valente*}

\begin{abstract}
Resumo:
O texto analisa a trajetória inicial de constituição da geometria como uma das matérias de ensino do curso primário brasileiro. $\mathrm{O}$ período de estudo compreende das primeiras décadas àquelas finais do século XIX. As fontes para a pesquisa levam em consideração, sobretudo, a documentação oficial e os livros didáticos. A empiria é analisada sob a ótica histórico-cultural. Analisam-se, em termos da definição das matérias a comporem os ensinos da escola primária, a apropriação das propostas de Condorcet, as discussões ocorridas no Congresso Nacional brasileiro e a elaboração de uma geometria prática para ensino nos anos iniciais escolares. Os resultados do estudo apontam para a sedimentação do desenho linear como uma geometria para o curso primário.
\end{abstract}

\section{Palavras-chave:}

geometria; geometria prática; história da educação matemática; matemática escolar; Condorcet.

* Professor Livre Docente do Departamento de Educação da Escola de Filosofia, Letras e Ciências Humanas da Universidade Federal de São Paulo (UNIFESP). Coordenador do Grupo de Pesquisa de História da Educação Matemática (GHEMAT) (www.unifesp. br/centros/ghemat). 


\title{
Brazil in the times of the Empire: the creation of geometry for primary schools
}

\section{Wagner Rodrigues Valente}

\begin{abstract}
:
The text analyzes the history of geometry as a content of primary education in Brazil. The period of study ranges from the first to the final decades of the nineteenth century. Official documentation and textbooks were the main research sources. The empirical study is analyzed under the historical-cultural perspective. With regard to the teaching of geometry, the following aspects are analyzed: the appropriation of Condorcet's proposals, the discussions and debates carried out at the Brazilian National Congress, and the elaboration of a practical geometry for primary school. Results show the sedimentation of the Linear Drawing as geometry for the primary school.
\end{abstract}

\section{Keywords:}

geometry; practical geometry; history of mathematics education; mathematics education; Condorcet. 


\section{Introdução}

Este texto analisa os primeiros passos de constituição de uma das matérias de ensino no curso primário brasileiro: a geometria. Assim, o estudo considera legítimo perguntar sobre as origens do ensino dessa matéria escolar nos primeiros anos escolares. A pesquisa remete ao tempo da Independência do Brasil, face à necessidade de estabelecer um marco de partida. Que referências justificam a introdução de conteúdos geométricos na escola de primeiras letras? Que geometria faz parte dessas primeiras discussões sobre sua inclusão na escola do ler, do escrever e do contar? Como a geometria se torna um saber escolar para o ensino primário no Brasil? Tais são as questões norteadoras deste estudo. No que toca ao material empírico da investigação, tomam-se as discussões legislativas, as leis e os decretos elaborados para orientar o ensino desse conteúdo escolar. Também os livros didáticos são considerados como fontes para este estudo. Em termos teórico-metodológicos, a empiria da pesquisa é lida sob o amparo de uma perspectiva histórico-cultural. Desse modo, torna-se possível a análise das mudanças no conteúdo da representação de uma "[...] geometria prática", lida já no período inicial da trajetória desse saber escolar (CHARTIER, 1990, 2007, 2008). São também mobilizados elementos vindos da história das disciplinas escolares, os quais levam em conta dinâmicas de imposição e apropriação, que esclarecem os processos envolvidos na produção dos saberes escolares (CHERVEL, 1990; JULIA, 2001). Por fim, o estudo dos livros didáticos de matemática é considerado como produção cultural, de modo semelhante a investigações realizadas anteriormente, em termos da história da educação matemática (VALENTE, 2008, 2011).

\section{A geometria para o curso primário brasileiro: uma proposta de Condorcet}

As discussões mais longínquas que se podem encontrar sobre o ensino de geometria no curso primário remetem às primeiras décadas do século XIX. A historiadora da educação Circe Bittencourt menciona que a obra de Condorcet é adaptada no Brasil e serve como referência inicial para os primeiros debates sobre a educação nacional: 
O texto educacional de Martim Francisco d'Andrada, "Memória sobre a reforma de estudos da Capitania de São Paulo", foi praticamente uma tradução adaptada da obra de Condorcet. Durante a Constituinte de 1823, a Comissão de Instrução Pública propôs que este trabalho servisse "de guia aos atuais professores e estímulo aos homens de letras para a composição de compêndios elementares, enquanto não se dá uma adequada forma à instrução pública [...]” (BITTENCOURT, 1993, p. 22-23).

A partir dessa referência, e na busca dos escritos de Condorcet, visando encontrar orientações para o ensino de matemática e, em específico de geometria, encontra-se o estudo Cinq Mémoires sur l'instruction publique ${ }^{1}$. Em particular, na Second Mémoire - De l'instruction commune pour les enfants, Condorcet discorre sobre os conhecimentos que devem estar presentes no curso primário, de quatro anos. Nos estudos do segundo ano, Condorcet menciona as primeiras noções de geometria (COUTEL; KINTZLER, 1989, p. 97). Continuando a leitura de suas "Mémoires", vê-se que, para o terceiro ano de estudos da escola primária, Condorcet, a partir das noções vistas no segundo ano, menciona que:

Das noções de geometria, o ensino deverá caminhar para os elementos de agrimensura, que serão desenvolvidos suficientemente para colocar em prática, no terreno, o agrimensor. Isso será feito não por um método cômodo, com simplificações que não fazem parte da prática, mas de um método geral, por meio do qual todos possam dificilmente esquecer os seus princípios. De sorte que os problemas encontrados não deverão impedir o trabalho prático. As crianças serão levadas a praticar a agrimensura na prática, nos terrenos; elas igualmente deverão fazer figuras, seja com régua e compasso, seja à mão livre (COUTEL; KINTZLER, 1989, p. 98-99, tradução nossa).

1 Nicolas Caritat, Marquês de Condorcet (1743-1794), matemático célebre, toma parte ativa na Revolução Francesa. Apresenta à Assembleia Legislativa, em nome do Comitê de Instrução Pública, um projeto de organização do ensino público. Suas propostas contêm o ideal de construção de uma escola conforme as orientações revolucionárias, cujo fim é a difusão do espírito iluminista. Em 1790, escreve as Mémoires sur l'instruction publique. Em seguida, apresenta o texto ao Comitê, a partir de sua instalação, em cinco de novembro de 1791. Condorcet propõe uma hierarquia das instituições escolares. Nela, o primeiro grau é formado por escolas primárias: uma escola para cada 400 habitantes: elas deverão ensinar os conhecimentos necessários a todos os cidadãos (NIQUE; LELIÈVRE, 1990, p. 129-130, tradução nossa). 
Por fim, no quarto ano, a proposta de Condorcet indica que os alunos deverão aperfeiçoar-se na agrimensura já que, com isso, também serão reforçados os conhecimentos aritméticos (COUTEL; KINTZLER, 1989, p. 101).

O texto de Martim Francisco d'Andrada, por sua vez, relativamente ao ensino de geometria, aponta para a organização dos conteúdos a serem ministrados no curso primário: para os estudos do $2^{\circ}$. ano, o ensino das “" [...] primeiras noções de geometria particularmente as que forem necessárias à medição dos terrenos [...]" e, ainda, “[...] exercitar o menino em traçar figuras já a mão, já com o compasso e régua [...]"; para os estudos do $3^{\circ}$. ano, a proposta prevê um "[...] aperfeiçoamento dos métodos de agrimensura, o que os fortifica no hábito da aritmética e geometria [...]” (RIBEIRO, 1945, p. 104).

Como bem se observa, a referência à discussão do ensino de geometria no curso primário brasileiro é, praticamente, uma tradução literal da proposta de Condorcet. $\mathrm{O}$ conteúdo desse ensino deve articular-se com a agrimensura: um ensino de geometria para a prática, uma geometria prática para a primeira etapa da escolarização.

\section{O que pensam os deputados sobre o ensino de geometria}

O primeiro fórum para discussão educacional, que se estabelece a partir da Independência, é o Congresso Nacional. Assim, nesse tempo distante, a análise da trajetória da presença dos ensinos de matemática, nas séries iniciais das escolas brasileiras, leva aos debates travados entre parlamentares na recém-constituída casa legislativa. Eles remetem ao ano de 1827 e estão registrados nos Anais da Câmara e do Senado:

[...] reunida a Legislatura, em 3 de maio de 1826, os dois primeiros meses foram fecundos em reclamações e iniciativas em prol da instrução popular. A comissão de instrução da Câmara dos Deputados, sem nenhum dado de recenseamento escolar, ofereceu à sua consideração um plano integral de estudos: escolas elementares, liceus, ginásios e academias, e cúpula do monumento, o Instituto Imperial do Brasil. Antes, em 1823, no projeto de Constituição se prescrevia: uma escola para cada termo, um ginásio para cada comarca e universidades nos mais apropriados lugares. Falhando estas grandiosas soluções para o problema da educação, a Câmara recebeu de sua comissão técnica, em junho de 1827, um modesto projeto de lei criando, de acordo com a realidade do momento, escolas primárias em todas as cidades, vilas e lugares mais populosos [...] (MOACYR, 1936, p. 180). 
No projeto, duas linhas sobre o que deveria ser ensinado no curso primário: "Os professores ensinarão a ler, escrever e contar, a gramática da língua nacional, os princípios de doutrina religiosa e de moral, proporcionados à compreensão [...]" (MOACYR, 1936, p. 181).

Colocado o projeto em discussão, os anais registram acalorados debates entre os parlamentares. Para o foco deste estudo, ressaltem-se aqueles relacionados aos ensinos de matemática. E eles são direcionados, quase que exclusivamente, para o ensino de geometria. Os anais registram que o primeiro parlamentar a manifestar-se sobre os conteúdos matemáticos a serem ensinados no curso primário é o deputado Ferreira França2: "[...] em vez de contar, como diz o projeto, prática das principais operações de aritmética e resolução prática dos problemas de geometria elementar [...]" (MOACYR, 1936, p. 183).

Logo a seguir a um aparte, França esclarece sua sugestão:

Não quero que o mestre ensine ou aponte o que é linha reta, quero que tome o compasso, descreva um triângulo sobre uma linha; isto não custa nada e é coisa mais fácil possível. Quero que o mestre prove o que ensina que os meninos aprendam como um carpinteiro ou pedreiro. Quero que o mestre ensine como há de dividir um triângulo retilíneo em duas partes iguais; quero que forme a sua escala, e que reduza da menor a maior grandeza. [...] Aprendemos com o uso. Muita gente não passa das primeiras escolas e quando vai aprender as artes encontra grandes dificuldades, se não tem algum conhecimento da geometria, assim como da primeira conta. (MOACYR, 1936, p. 183184).

Terminada a primeira manifestação de Ferreira França, toma a palavra outro parlamentar a objetar contra as modificações propostas, com a inclusão

2 O médico Antônio Ferreira França (1771-1848) nasce e morre na Bahia, leciona até 1837 na faculdade de medicina dessa cidade as disciplinas de higiene, etiologia, patologia interna e terapêutica. Forma-se em matemática, filosofia e medicina (1798) na Universidade de Coimbra. Dá aulas de aritmética, geometria e grego. É médico da Santa Casa da Misericórdia, diretor do Liceu Provincial da Bahia, vereador e deputado. Não deixa publicações, apenas escreve um manuscrito de "[...] preleções de geometria [...]", projetos e pareceres legislativos (BARROS, 1998, p. 436). 
de conteúdos de geometria. Trata-se de Augusto Xavier de Carvalho ${ }^{3}$, que assim se manifesta:

[...] o estado de atrasamento em que se acha desgraçadamente a educação no Brasil fará com que se formos a exigir de um professor do primeiro ensino, do qual depende a felicidade dos cidadãos, requisitos maiores não tenhamos professores. Se exigirmos de um mestre de primeiras letras princípios de geometria elementar, dificultosamente se acharão; talvez apareçam muitos na Corte e nas províncias de beira-mar haja alguns; mas daí por diante haverá muito poucos ou nenhum. Por isso eu me contentaria que os mestres soubessem as operações de aritmética maquinalmente; eu aprendi assim [...] (MOACYR, 1936, p. 184).

A essa intervenção, replica Cunha Mattos" : “[...] os princípios de geometria são de última necessidade até para ser pedreiro ou carpinteiro [...]" (MOACYR, 1936, p. 184). Outro aparte é dado a Odorico Mendes 5 , que apoia Ferreira França sobre a necessidade de estudos elementares de

3 Augusto Xavier de Carvalho, bacharel em ciências jurídicas e sociais. Deputado na 1. ${ }^{\text {a }}$ Assembleia Constituinte, pela Paraíba, em 1823. Deputado à Assembleia Geral, pela Paraíba, nas $1 .^{\mathrm{a}}$ e $2 .^{\mathrm{a}}$ legislaturas, respectivamente, de 08.05.1826 a 03.09.1829, e de 03.05.1830 a 06.10.1833 (COLÉGIO..., 2011).

4 O marechal de campo Raimundo José da Cunha Mattos (1776-1839) tem contato com a Ilustração na Real Casa Pia de Lisboa. Na Escola Regimental de Artilharia do Algarve, é treinado com base nas ideias e práticas implantadas pelo Conde Lippe. É veterano da guerra do Roussillon, serve em São Tomé e Príncipe, é governador de Armas de Goiás, deputado na Assembleia Legislativa do Império Brasileiro e um dos fundadores do Instituto Histórico e Geográfico Brasileiro (RODRIGUES, 2008, p. vii).

5 Político, publicista, humanista e um dos mais antigos tradutores do Brasil, Manoel Odorico Mendes nasce em 24 de janeiro de 1799, em São Luís, Maranhão, descendente de uma das famílias mais tradicionais de seu estado. Ali reside até os 17 anos quando, em 1816, é enviado pelo pai a Portugal para cursar Medicina, na Faculdade de Medicina da Universidade de Coimbra. Em 1824, após o falecimento do pai, retorna ao Brasil, em um período de grandes tensões internas e de instabilidade, decorrentes da independência brasileira, ocorrida dois anos antes. Incitado por forte patriotismo, inicia sua atividade como publicista, redigindo o jornal O Argos da lei, em janeiro de 1825. Por influência do jornal, é eleito deputado da primeira Assembleia Legislativa do Brasil, e transfere-se para a capital carioca em meados de 1830, onde se afirma como político e jornalista, escrevendo para inúmeros jornais de São Paulo e do Rio de Janeiro. Mantém-se na política até 1847, quando encerra seu último mandato como deputado. Falece aos 65 anos, em 17 de agosto de 1864, em Londres, Inglaterra (DICIONÁRIO..., 2011). 
geometria (MOACYR, 1936, p. 185). Lino Coutinho ${ }^{6}$, outro parlamentar, apoia a inclusão de estudos de geometria, mencionada por Ferreira França: “[...] aquele saber escrever por via de compasso e de régua, as primeiras e mais essenciais figuras da geometria [...]" (MOACYR, 1936, p. 186). Outro parlamentar manifesta-se sobre o ensino de geometria:

O Sr. Vasconcelos é pelo estudo da geometria de aplicação imediata no campo, no terreno da escola. Para que geometria gráfica? Qual a sua utilidade? "Está demonstrado que a matemática não sendo aplicada não presta utilidade senão para fazer $=a X \mathrm{e}$ perder tempo" [...] (MOACYR, 1936, p. 186).

Ainda de acordo com Primitivo Moacyr, “[...] após 30 emendas e várias sugestões e críticas da tribuna, o projeto, oferecido a oito de julho, é aprovado com modificações na sessão de 28 de julho [...]". No que toca aos conteúdos, que devem estar presentes no curso primário, a Lei discrimina: "Os professores ensinarão a ler, escrever, as quatro operações de aritmética, prática de quebrados, decimais e proporções, as noções mais gerais de geometria prática, a gramática da língua nacional [...]” (MOACYR, 1936, p. 189).

Desse modo, nasce a lei de 15 de outubro de 1827, a primeira lei sobre a instrução no Brasil. Vê-se que, em grande medida, os debates entre os parlamentares para fixação dos conteúdos de ensino para a escola de primeiras letras atentam para as especificidades da matemática escolar. O programa que entra em pauta inicialmente "[...] ler, escrever e contar, gramática da língua nacional, princípios de doutrina religiosa e de moral, proporcionadas à compreensão dos meninos; havia também para as meninas o coser e bordar [...]” (MOACYR, 1936, p. 199) sofre emendas, transformando-se em

6 José Lino Coutinho nasce em Salvador, em 31 de março de 1784. Realiza os estudos de humanidades, parte para Portugal, ingressando na Universidade de Coimbra, onde recebe o grau. Concluído o curso médico, viaja para a França e Inglaterra, onde aperfeiçoa seus conhecimentos. Voltando para o Brasil, fixa-se em sua terra natal, onde exerce a clínica e toma parte proeminente na luta pela Independência do Brasil. Nomeado membro da Junta Provincial, é eleito, em 1821, deputado às cortes portuguesas. Depois da vitória das forças brasileiras, é eleito deputado às duas primeiras legislaturas, fazendo-se opositor do imperador D. Pedro I. De 1826 a 1829, é eleito deputado geral (MÉDICOS..., 2011). 
[...] ler, escrever, as quatro operações de aritmética, prática de quebrados, decimais e proporções, as noções mais gerais de geometria prática, a gramática da língua nacional, os princípios da moral cristã e de doutrina de religião católica e apostólica romana, proporcionados à compreensão dos meninos; preferindo para o ensino da leitura a Constituição do Império e história do Brasil (MOACYR, 1936, p. 200).

Este é o primeiro programa decretado pela Assembleia Geral Legislativa (lei de 15 de outubro de 1827) e que se mantém nas escolas de ensino do município neutro (Corte) até 1854, quando se promulga uma reforma de instrução primária e secundária na capital do Império (MOACYR, 1936, p. 562).

\section{A primeira geometria do curso primário: uma geometria prática}

Desde Condorcet, em sua versão adaptada por Martim Francisco, a primeira referência a constituir parâmetro para a organização da escola de primeiras letras no Brasil indica que o ensino de geometria deve ter caráter prático; um ensino que dê condições para certo exercício profissional, para a medida de terrenos, para a agrimensura. Assim, a geometria para os que iniciam a escola constitui saber específico, técnico, instrumental. Desde esse longínquo tempo, ao que tudo indica, fica caracterizada a representação de que, para a escola de primeiras letras, necessita-se de uma geometria prática. É nesses termos que a geometria é tratada pela lei de criação das escolas primárias. Tal lei tem como antecedente a Carta outorgada por Pedro I, em 1824, que estabelece, dentre outras coisas, a gratuidade do ensino primário. A lei de 15 de outubro de 1827, assim, refere-se à criação de escolas primárias em todas as cidades e vilas com a adoção do método lancasteriano ${ }^{7}$.

7 Em breves termos, o método lancasteriano, monitorial ou mútuo contrapõe-se aos métodos de ensino individual e simultâneo, “[...] onde o agente de ensino é o professor, no método mútuo, é o aluno que é investido dessa função: o princípio fundamental deste método consiste [...] na reciprocidade de ensino entre os alunos, com o mais capaz servindo de professor àquele que é menos capaz, e é assim que a instrução é ao mesmo tempo simultânea, pois todos avançam gradualmente, seja qual for o número de alunos [...]" (LESAGE, 1999, p. 11). 
Estabelecida essa normativa de funcionamento das escolas primárias, por certo, há iniciativas para a elaboração de textos e referências para o ensino, no que ficou conhecido como escola de primeiras letras.

Do ponto de vista do ensino de geometria, há que se ter mais precisão sobre o significado de ensinar "as noções mais gerais de geometria prática". É necessário que haja orientação para esse ensino. Como ensinar essa geometria prática através do método mútuo/lancasteriano? E, o que ensinar?

Não irá tardar para que seja publicada uma obra que intenta dar resposta a essas questões. Ela visa a atender a essa organização legislativa que situa, junto do ler, escrever e contar, o ensino de uma geometria prática. Trata-se do livro cuja capa traz os dizeres: Princípios do desenho linear compreendendo os de geometria prática, pelo método do ensino mútuo, extrahidos de L. B. Francoeur, dedicados aos amigos da instrucção elementar no Brasil, por A. F. de P. e Iollanda Cavalvanti d'Albuquerque. Rio de Janeiro, na Imperial Typographia de P. Plancher-Seignot, rua d'Ouvidor, no. 95, primeiro andar, 1829".

Logo à segunda página da obra consta uma "Advertência" que confirma a motivação para a edição do livro:

Este trabalho foi empreendido a fim de facilitar aos Professores Públicos a execução da Lei de 15 de Outubro de 1827; as pessoas, que desejarem maiores ilustrações sobre esta matéria, poderão consultar o original, donde foram extraídos estes princípios; isto é, o desenho linear, por Francoeur; impresso em Paris, no ano de 1819 (ALBUQUERQUE, 1829, p. 2).

O livro, como se lê no título, tem por referência Francoeur. Relativamente a esse autor, sabe-se que cabe a Louis-Benjamin Francoeur ${ }^{9}$ o pioneirismo

8 O livro pertence ao acervo da Fundação Biblioteca Nacional do Rio de Janeiro. Com objetivo diverso deste estudo - que trata dos ensinos de geometria na escola primária - o texto traduzido por Holanda Cavalcanti de Albuquerque é minuciosamente analisado pela pesquisadora Gláucia Maria Costa Trinchão (2008) no desenvolvimento de sua tese de doutoramento. Nessa investigação, a autora trata do estudo do desenho.

9 “O matemático francês Louis-Benjamin Francoeur vive em Paris entre 1773 e 1849, segue a carreira militar e acadêmica. Enquanto militar serve ao exército e participa de várias batalhas nas campanhas francesas sob o comando de Napoleão Bonaparte e na carreira acadêmica atuou como professor de Matemática na École Polytechnique e, em seguida, no Lycée Charlemagne [...]” (TRINCHÃO, 2008, p. 266). 
de sistematizar os conteúdos de desenho para as escolas de ensino mútuo. A obra de Francoeur, intitulada Dessin Linéaire et Arpentage, pour touts les écoles primaires, quel que soit le mode d'instruction qu'on y suit, com publicação em 1819, é referência para o ensino em Portugal e no Brasil, tendo sido aprovada pela Mesa Censória (TRINCHÃO, 2008, p. 88). O trabalho desse autor francês adota os princípios de Pestalozzi, construindo um texto elementar a partir da geometria e geometria descritiva, com vistas à capacitação de mão de obra técnica para a indústria francesa ${ }^{10}$ (TRINCHÃO, 2008, p. 25).

Dez anos depois da publicação do livro de Francoeur, e tendo a obra, desde o princípio, constituído referência para cursos em Portugal e no Brasil, conforme se mencionou anteriormente, tem publicação o texto de Holanda Cavalcanti de Albuquerque ${ }^{11}$, Princípios do desenho linear compreendendo os de geometria prática, pelo método do ensino mútuo. Digno de nota é verificar que a adaptação da obra de Francoeur é realizada por um parlamentar, que ao tempo das discussões e emendas que resultaram na Lei de 1827, manifestou-se, de certo modo, em desacordo com a adoção do método lancasteriano. Holanda Cavalcanti de Albuquerque assim pronunciou-se nos debates legislativos:

10 Relativamente à questão profissional, o autor francês destaca que "a ciência do desenho é indispensável para aqueles que trabalham na construção de prédios, a todos os pedreiros, marceneiros, carpinteiros, serralheiros, ladrilhistas, aos que trabalham com fogões, àqueles que fabricam móveis, que trabalham com as coisas da moda e do gosto, tais como os entalhadores, fundidores, douradores, relojoeiros, marmoristas, alfaiates; aos que constroem instrumentos como os ópticos, engenheiros, mecânicos, fabricantes de tintas etc. e poderia citar quase todas as profissões [...]" (FRANCOEUR, 1839, p. iv-v).

11 Antônio Francisco de Paula de Holanda Cavalcanti de Albuquerque, o visconde de Albuquerque (1797-1863) inicia-se na carreira militar ainda criança, atingindo o posto de Tenente-Coronel, no qual se reforma, em novembro de 1832. É eleito Deputado por sua província na $1^{\mathrm{a}}$ legislatura de 1826 a 1829 . Conselheiro de Estado ocupa a pasta da Fazenda em quatro Gabinetes. Nos dois primeiros períodos, enfrenta a situação crítica do estado econômico do País. Em 1846, volta ao cargo; nesse período reorganiza as Recebedorias das Rendas Internas, cria as da Bahia, Pernambuco, Maranhão, Pará e São Pedro do Sul, atual Rio Grande do Sul, com a atribuição de arrecadar tributos, o que até então era feito pelas Alfândegas. No Gabinete do Marquês de Olinda, em 1862, pela quarta e última vez, exerce o cargo de Ministro da Fazenda. Chamado para outras pastas ocupa a da Marinha também por quatro períodos; dirige ainda as pastas da Guerra e do Império (BRASIL, 2011). 
Que se dê ao mestre o arbítrio de ensinar pelo sistema que julgar melhor e não se deve obrigá-lo ao método de Lancaster; a escola de ensino mútuo é diferente das outras? "Inquire o Sr. Holanda Cavalcanti; que ainda pede que as lições de primeiras letras sejam dadas somente de manhã (das 8 horas ao meio-dia); feriado na quinta-feira, não havendo dia santo, na semana; férias da véspera de Natal ao dia de Reis [...] (MOACYR, 1936, p. 188).

A obra em português, adaptada do livro de Francoeur, desde o título já revela singularidades: acrescenta a expressão "geometria prática" não presente no livro do original francês. Veja-se, a seguir (Figura 1), a capa da obra.

O livro, além disso, apresenta atividades a serem desenvolvidas em quatro níveis (quatro classes de ensino), utilizando apenas a parte inicial da obra de Francoeur, que indica oito classes. Por certo, a adaptação visa aos quatro anos do curso primário tão somente. Nela, para a primeira classe, há itens como, por exemplo: dividir um segmento em seis partes iguais; por um ponto fora de uma reta, construir uma perpendicular à reta; construir um triângulo equilátero; dividir um ângulo em dez partes iguais. Na segunda

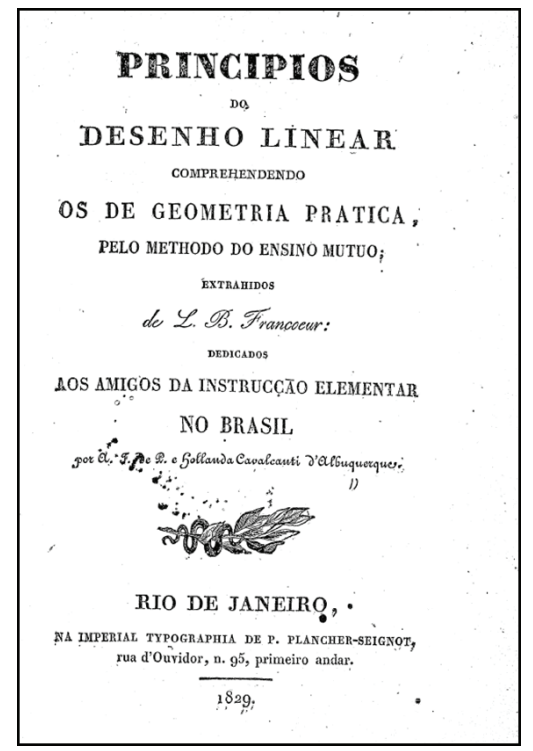

Figura 1. Capa do livro Princípios do desenho linear de 1829. 
classe, são exemplos de atividades: construir um trapézio, sendo dadas as bases e a altura; construir um paralelepípedo. Para a terceira, construir uma circunferência, sendo dados o centro e o raio; circunscrever um quadrado num círculo dado; inscrever um octógono regular num círculo. Por fim, na quarta classe, há atividades como: construir um transferidor, construir uma elipse etc.

Ao contrário do que se possa imaginar, pelos exemplos de atividades mencionados, elas não são propostas para o exercício de construções geométricas, com régua, compasso, esquadro etc. As atividades devem ser realizadas pelo desenho. Explicando melhor: os alunos são levados a desenhar à mão livre, as figuras geométricas, com a máxima precisão possível.

$\mathrm{Na}$ análise que o pesquisador Renaud D'Enfert realiza sobre o desenho linear na escola primária francesa, explicita-se melhor o valor pedagógico das propostas de Francoeur, adaptadas por Albuquerque:

Os exercícios sistemáticos de desenho geométrico à mão livre, elaborados como uma ferramenta destinada a afinar os sentidos, levando-os até mesmo ao mais alto ponto da perfeição, fazendo do corpo um instrumento próprio para traçar as figuras. $\mathrm{O}$ sucesso do novo ensino é avaliado especialmente pela destreza adquirida pelos jovens alunos, à custa de inúmeros exercícios, destreza que surpreende o público quando da entrega de prêmios de fim de ano. Mas o que encanta, não é tanto a qualidade estética dos desenhos realizados pelos alunos, mas a virtuosidade desses. Além do seu aspecto sensacional, esses exercícios de destreza não são desprovidos de intenções educativas, bem ao contrário. Insistir sobre a habilidade manual equivale a eclipsar o aspecto "liberal" do desenho em proveito de uma visão mais utilitária, mas também a disciplinar o gesto e os comportamentos (D'ENFERT, 2007, p. 45).

Desse modo, a partir do treino em traçar uma linha reta, caminha o aluno para o traçado de ângulos, de polígonos, de sólidos geométricos à mão livre. Instados a comparar medidas visualmente, os alunos desenham as figuras. Depois, ao professor (o monitor - o decurião -, no caso do método mútuo) cabe a verificação da precisão dos desenhos, a partir do uso dos instrumentos de medida (régua, compasso, transferidor etc.).

Dessa maneira, desde as primeiras páginas, nas Instruções Gerais para o Professor é possível ler: 
As dificuldades, que se encontrão nos estabelecimentos das Escolas segundo método do Ensino Mutuo, desaparecem imediatamente, assim que estas se acham organizadas: o trabalho havido na organização regula de uma vez a marcha, e o progresso da Escola. O Professor começa formando Decuriões, por meio de lições particulares dadas a um pequeno número de pessoas inteligentes, exercitando-as aos mandamentos, que estas por seu turno farão transmitir às outras, e acostumando-as a compreender as ordens, que a voz, ou o gesto lhes transmite.

Para o ensino do desenho linear por este método deverá, pois o Professor, consagrar algumas horas em cada dia a formar os Decuriões de diferentes classes. Ora supondo, que se queira introduzir o ensino do desenho nas escolas de primeiras letras, já organizadas segundo o sistema do ensino mútuo, deverá o Professor escolher na classe mais adiantada oito a dez discípulos; far-se-á seu Decurião, e os exercitará à pratica dos preceitos, que vamos desenvolver.

A maior parte destes preceitos é reservada exclusivamente ao Professor; mas, por serem interditos nas classes, não deixa de dever ser ensinado a um pequeno número de discípulos escolhidos dentre os mais inteligentes (ALBUQUERQUE, 1829, p. 1-2).

Ao aluno - o discípulo - cabe o exercício e o treino do olhar, e sua transferência precisa ao traçado das figuras geométricas:

Convém, especialmente, que o discípulo se familiarize com as medidas métricas lineares e de capacidade; o olho deve-lhe ser um regulador tão certo, como se ele servisse de um metro: basta de habilitá-lo a isso, para que o sentido da vista lhe seja um guia quase infalível (ALBUQUERQUE, 1829, p. 6).

O trecho a seguir exemplifica uma das atividades adaptadas por Albuquerque, na qual se observa a construção de retas paralelas sem instrumentos. Essas tarefas constituem, muito provavelmente, os exercícios iniciais de geometria propostos aos alunos da escola de primeiras letras. Observa-se, também, que o livro todo se apresenta como uma sequência de textos com instruções de construções a serem feitas pelos alunos.

23. Por um ponto conduzir uma reta paralela à outra, fig. 6 . Tendo tirado uma reta, o discípulo marcará um ponto qualquer fora dela: muito convirá fazer variar a posição. Por este ponto conduzirá uma reta paralela à primeira, isto é, cujos extremos fiquem igualmente distantes dos da outra linha, sendo esta também igual à $1^{\text {a }}$. Veja-se o problema 19. 
Quando o Decurião quiser servir-se de esquadro, aplicá-lo-á sobre a tábua fazendo coincidir um dos lados deste triângulo com a linha, que ele tiver traçado. Depois encostando sua régua a um dos outros lados do triângulo, apoiará a mão esquerda sobre ela para a ter fixa, e fará escorregar o esquadro ao longo desta régua: parando em fim o esquadro, quando lhe parecer. A linha, que traçar sobre o lado, que coincidir com a primeira, será paralela a esta. O Decurião no princípio dificultosamente fixa a régua, mas pode ser ajudado por um discípulo, que a terá imóvel, em quanto ele fará escorregar o esquadro, e traçará a paralela.

Este processo sendo de muito uso nas artes importa que se faça bem conhecer; convém notar, que o Decurião é quem unicamente tem direito de servir-se dos instrumentos. Mas os discípulos, que os vêm empregar, aprendem o seu uso sem preceitos, e habilitam-se a servir-se deles, e ser Decuriões (ALBUQUERQUE, 1829, p. 24-25).

Note-se, ainda, que as figuras, as representações dos desenhos a serem traçados, encontram-se ao final do livro. Os desenhos apresentados são tão precisos que chegam a dar a impressão, ao leitor desatento, de que foram feitos com instrumentos. No entanto, são construções à mão livre. Veja-se, a seguir, um exemplo de quadro de exercícios a serem feitos por alunos da primeira classe (Figura 2).

Traduzida e adaptada para atender à lei de 1827, a obra de Holanda Cavalcanti, em boa medida, revela-se um manual de desenho, em que os alunos são ensinados a treinar o olhar na avaliação de medidas, espaços e formas, traçando a mão livre elementos geométricos. Desse modo, ao introduzir o desenho preciso, através do treino do olhar, da proporção do traçado etc., a obra leva ao conhecimento dos elementos da geometria. Uma geometria praticada através do desenho, do desenho linear, do desenho à mão livre das linhas e formas geométricas.

\section{E o desenho linear faz escola como geometria para o ensino primário}

As considerações anteriores demarcam um ponto de partida para a análise da elaboração de uma geometria escolar a ser ensinada na escola de primeiras letras. Cabe perguntar em que medida as orientações iniciais, os 


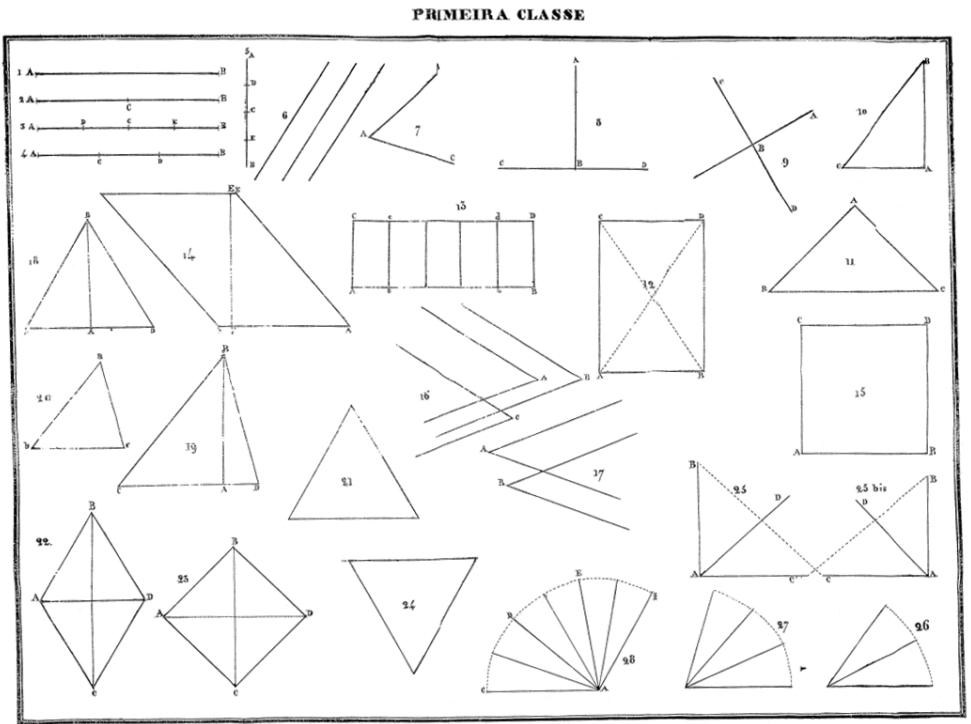

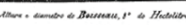

Figura 2. Exercícios feitos a mão livre, colocados ao final do livro Princípios do desenho Linear de 1829.

debates, a adaptação de obra estrangeira para atender a diretivas oficiais, nesse estágio primeiro, referencia o ensino primário em tempos posteriores.

Discussões legislativas, leis e decretos constituem orientadores para o ensino. Sabe-se bem que esses dispositivos legais não são sinônimos do que ocorre no cotidiano das escolas. É no embate das obrigações dadas por lei com as condições efetivas de ensino, que é forjada a dinâmica de elaboração dos saberes escolares e, em específico, dos cursos de matemática para a escola de primeiras letras.

Como se sedimenta uma geometria no curso primário a partir das primeiras referências para seu ensino?

Os livros didáticos podem ser tomados como fontes para esse estudo. Saliente-se, no entanto, que as obras didáticas têm peso relativo diferente. Aquelas que atravessam décadas, com número grande de edições, sugerem ter tido penetração significativa no cotidiano escolar. Desse modo, constituem fontes privilegiadas para o estudo de como um saber organizou-se para estar no cotidiano escolar. Noutros termos, podem revelar como, no caso da 
matemática, os ensinos de geometria sedimentaram-se como saber escolar para o curso primário.

Chegadas as últimas décadas do século XIX, surgem muitas obras didáticas que irão incluir a geometria para as séries iniciais. Destaque-se o livro didático Desenho linear ou elementos de geometria prática popular de Abílio Cesar Borges ${ }^{12}$, de 1882 . Tudo indica que a obra teve grande penetração nas escolas, a julgar pelo número de edições ${ }^{13}$. De pronto, chama a atenção o paralelo colocado no título da obra: Desenho linear ou elementos de geometria prática. Nessa escrita, o desenho linear passa a constituir sinônimo de geometria. Assim, para o curso primário, o ensino de geometria identificase com desenho linear, um desenho de linhas, de figuras da geometria.

No livro de Borges (1882), a geometria apresenta-se em onze capítulos: noções preliminares do ponto e das linhas, posições de duas linhas retas e curvas, posição relativa das linhas, dos ângulos, dos polígonos, dos triângulos, dos quadriláteros, das figuras formadas por linhas curvas, dos sólidos, dos poliedros, dos sólidos redondos.

Novamente será preciso destacar que, ao contrário do que essa listagem de conteúdos pode sugerir, não há construções geométricas, não há um ensino orientador de uso de régua, compasso e instrumentação para que sejam construídas as figuras e as formas geométricas.

A análise interna da obra mostra que, em grande medida, o autor ocupa-se da nomenclatura dos elementos geométricos, suas variedades, formas, modos de se apresentar. Não há intenção de levar o aluno a realizar construções. Caber-lhe-á apenas desenhar essas figuras e saber o nome de cada uma delas.

12 Abílio Cesar Borges (1824-1891) nasce na Bahia e, em 1858, troca sua carreira de médico pela atividade educacional ao fundar, nesse ano, o Ginásio Baiano; em 1871, transfere-se para o Rio de Janeiro, instalando o Colégio Abílio. Em 1881, ganha de D. Pedro II o título de barão de Macaúbas. Sobre esse personagem, há muitos estudos. Um deles, de autoria de Gondra \& Sampaio (2010), resume do seguinte modo sua trajetória: médico, gestor da instrução pública, dono de escola, homem de imprensa, autor de livros de destinação escolar, viajante, conselheiro da instrução, Dr. Abílio César Borges protagonizou algumas iniciativas na esfera pública e privada, como forma de demonstrar princípios educativos que abraçara no que se refere aos métodos de ensino, aprendizagem da leitura e escrita, aritmética e geometria, educação infantil e castigos corporais, por exemplo.

13 A obra é publicada até, pelo menos, a década de 1960, quando alcança a sua 42a . edição! (PFROMM NETO, 1974). 
Considerem-se, como exemplo ilustrativo, as primeiras linhas do capítulo II do livro de Borges: "Posição das linhas - posição das linhas retas":

Posição de uma linha reta é o sentido da sua direção relativamente à superfície da terra ou a outra linha. Dois pontos bastam para determinar a posição de uma reta. Toda reta, quer no espaço, quer em um plano, pode ocupar-se três posições: - horizontal, vertical e inclinada. Horizontal é a reta que segue a direção da superfície da agua tranquila; e é por isso também chamada linha de nível. A linha seguinte, EF, está em posição horizontal ou de nível E F (BORGES, 1882, p. 11).

Sem estender a análise, é possível dizer que Desenho linear ou elementos de geometria prática popular, de Abílio Cesar Borges, sedimenta a organização de uma geometria para a escola de primeiras letras como desenho linear, desenho de linhas. E, neste caso, o desenho linear faz escola como geometria.

\section{Revolução francesa, Condorcet e a primeira geometria para ensino primário brasileiro}

Calcado no iluminismo francês, chegam ao Brasil os ventos da Revolução, trazendo as primeiras referências para os debates sobre a instrução pública. Na tradução das Memórias de Condorcet, Martim Francisco expõe a primeira forma como deve ser pensada e ensinada a geometria para o curso primário no Brasil: uma geometria prática. Deverá ela ser vista como útil às lides da agrimensura, da medida de terras. Ela é pensada por Condorcet, por certo, como elemento de sistematização do saber a ser utilizado nos campos, por aqueles que a revolução acabara de libertar.

Em meio aos debates parlamentares, sedimenta-se a importância de incluir a geometria junto à tríade do "ler, escrever e contar". Serão os deputados com formação matemática - médicos e militares, sobretudo - como é possível ler nas notas biográficas, aqueles que mais ativamente defendem a inclusão desse saber elementar no curso primário. Mas, ela terá que ter, também, caráter prático: "as noções mais gerais da geometria prática".

A análise do livro de Holanda Cavalcanti - uma das primeiras, senão a primeira obra - a interpretar a demanda legislativa de uma geometria prática para o ensino primário - mostra que a geometria será prática se os alunos 
são levados a trabalhar com as figuras geométricas. O exercício do olhar, na avaliação de medidas e formas, deve conduzir os exercícios à mão livre das figuras da geometria. Associar esse ensino de geometria à agrimensura, à medição de terrenos, como é a intenção inicial, desde Condorcet, parece ter sido deixado de lado. O caráter prático é dado pelas construções de linhas, de ângulos, de figuras e, mesmo, dos desenhos em perspectiva de sólidos geométricos. A representação do caráter prático migra, ao que parece, de atividades rurais - como a medição de terrenos - para as profissões que têm lugar nas vilas e cidades francesas ao tempo da escrita da obra de Francoeur. E, mais, a forma prática dessa geometria deverá ser demonstrada no âmbito escolar: a atividade dos alunos com o desenho das formas geométricas. Não mais o campo, o terreno, como lugar de ação dos alunos é prova do caráter prático... Assim, nesses tempos iniciais, logo ficam à mostra, as transformações de significado da geometria prática. De qualquer modo, nesses dois primeiros momentos, a justificativa para os ensinos das "primeiras noções de geometria prática" liga-se a bases a serem adquiridas na escola, para o exercício de ofícios profissionais: seja na agrimensura, seja no trabalho com o desenho, presente, como menciona Francoeur, numa ampla gama de atividades do mundo do trabalho.

Outros tempos virão, a seguir, com o crescimento da produção e circulação de livros didáticos para o curso primário. A análise dessas obras para o ensino mostra a permanência da concepção de que, para as primeiras letras, cabe uma geometria especial, prática, que leve em conta o desenho, o desenho das linhas, o desenho linear.

Diferentemente de outros estudos que levam em conta a construção do desenho enquanto uma matéria própria para o curso primário, um saber que deverá se agregar ao ler, escrever e contar, a análise empreendida neste trabalho considera que o desenho linear constitui uma geometria para o curso primário.

\section{Referências}

Albuquerque, Antônio Francisco de Paula de Holanda Cavalcanti. Princípios do desenho linear compreendendo os de geometria prática pelo método do ensino mútuo: Extraídos de L. B. Francoeur. Rio de Janeiro: Na Imperial Typographia de P. Plancher-Seignot, 1829. 
Barros, Pedro Motta. Alvorecer de uma nova ciência: a medicina tropicalista baiana. História, Ciências, Saúde, Manguinhos, v. 4, n. 3, p. 411-459, nov./ fev. 1998.

Bittencourt, Circe Maria Fernandes. Livro didático e conhecimento histórico: uma história do saber escolar. 1993. Tese (Doutorado em História)-Faculdade de Filosofia, Letras e Ciências Humanas da Universidade de São Paulo, São Paulo, 1993.

Borges, Abílio Cesar. Desenho linear ou elementos de geometria pratica popular. 2. ed. Rio de Janeiro: Francisco Alves, 1882. [Original de 1878].

Brasil. Ministério da Fazenda. Ministros de Estado da Fazenda. Antonio Francisco de Paula Hollanda Cavalcanti de Albuquerque. Disponível em: $<\mathrm{http}: / / \mathrm{www}$. fazenda.gov.br/portugues/institucional/ministros/dom_pedroI012.asp>. Acesso em: 15 mar. 2011.

CHARTIER, Roger. A história cultural: entre práticas e representações. Lisboa: Difel; Rio de Janeiro: Bertrand Brasil S.A., 1990.

. La historia o la lectura del tiempo. Barcelona: Editorial Gedisa, S.A., 2007.

. Escuchar a los muertos com los ojos. Buenos Aires; Madrid: Katz Editores, 2008.

Chervel, André. História das disciplinas escolares: reflexões sobre um campo de pesquisa. Teoria \& Educação, Porto Alegre, v. 2, p. 177-229, 1990.

Colégio Brasileiro de Genealogia. Arquivos genealógicos. Disponível em: $<$ http:// www.cbg.org.br/arquivos_genealogicos_p_04.html>. Acesso em: 18 fev. 2011.

Coutel, Charles; Kintzler, Catherine. Condorcet: Écrits sur l'instruction publique. Paris: Edilig, 1989.

Dicionário de Tradutores Literários no Brasil. Odorico Mendes. Disponível em: $<$ http://www.dicionariodetradutores.ufsc.br/pt/OdoricoMendes.htm\#b $>$. Acesso em: 18 fev. 2011.

D’EnFERT, Renaud. Uma nova forma de ensino de desenho na França no início do século XIX: o desenho linear. História da Educação, Pelotas, n. 22, p. 31-60, maio/ ago. 2007. 
Francoeur, Louis Benjamin. Dessin Linéaire et Arpentage: pour toutes les écoles primaires. Paris: Chez Louis Colas, Libraire et Chez Bachelier, Libraire, 1839.

Gondra, José Gonçalves; SAmpaio, Thiago Sampaio. Ciência pela força? Dr. Abílio Cesar Borges e a propaganda contra o emprego da palmatória e outros meios aviltantes no ensino da mocidade (1856-1876). Acta Scientiarum Education, Maringá, v. 32, n. 1, p. 75-82, 2010. http://dx.doi.org/10.4025/actascieduc. v32i1.9482

Julia, Dominique. A cultura escolar como objeto histórico. Revista Brasileira de História da Educação, Campinas, n. 1, p. 9-43, jan./jun. 2001.

Lesage, Pierre. A pedagogia nas escolas mútuas do século XIX. In: Bastos, Maria Helena Camara; Faria Filho, Luciano Mendes de (Orgs.). A escola elementar no século XIX: o método monitorial/mútuo. Passo Fundo: EDIUPF, 1999.

Médicos Ilustres da Bahia e de Sergipe. José Lino Coutinho. Disponível em: $<$ http://medicosilustresdabahia.blogspot.com/2011/02/218-jose-lino-coutinho. html>. Acesso em: 10 abr. 2011.

Moncyr, Primitivo. A instrução e o Império. Brasiliana Eletrônica, 1936. 1 v. Disponível em: $<$ http://www.brasiliana.com.br/obras/a-instrucao-e-o-imperio-1vol/pagina/181/texto>. Acesso em: 20 mar. 2011.

Nique, Christian; Leliève, Claude. Histoire biographique de l'enseignement en France. Paris: Éditions Retz, 1990.

Pfromm Neto, Samuel. O livro na educação. Rio de Janeiro: Primor/INL, 1974.

Ribeiro, José Querino. A memória de Martim Francisco sobre a reforma dos estudos da capitania de São Paulo. Separata do: Boletim LIII da F.F.L.C. USP, São Paulo, n. 5, 1945.

Rodrigues, Neuma Brilhante. Nos caminhos do Império: a trajetória de Raimundo José da Cunha Mattos. 2008. Tese (Doutorado em História)-Universidade de Brasília, Brasília, 2008. Disponível em: <http://repositorio.bce.unb.br/ bitstream/10482/5134/1/2008_NeumaBRodrigues.pdf $>$. Acesso em: 02 abr. 2011.

Trinchão, Gláucia Maria Costa. O desenho como objeto de ensino: história de uma disciplina a partir dos livros didáticos luso-brasileiros oitocentistas. 2008. Tese (Doutorado em História)-Universidade do Vale do Rio dos Sinos, São Leopoldo, 2008. 
VALENTE, Wagner Rodrigues. Livro didático e educação matemática: uma história inseparável. Zetetiké, Campinas, v. 16, n. 30, p. 139-161, jul./dez. 2008.

- A Matemática na formação do professor do ensino primário: São Paulo, 1875-1930. São Paulo: Annablume; FAPESP, 2011.

Endereço para correspondência:

Wagner Rodrigues Valente Estrada do Caminho Velho, 333

Bairro dos Pimentas

Guarulhos - SP

CEP: 07252-312

E-mail: wagner.valente@unifesp.br

Recebido em: 16 abr. 2012

Aprovado em: 9 ago. 2012 